\section{Entre neurônios e sinapses: as contribuições de Cajal e Athias para a medicina ibérica entre os séculos XIX e XX}

\author{
Between neurons and
}

synapses: the contributions of Cajal and Athias to Iberian

medicine between

the nineteenth and twentieth centuries

\section{Isabel Amaral}

Professora, Centro Interuniversitário de História das Ciências e da Tecnologia, Faculdade de Ciências e Tecnologia/ Universidade Nova de Lisboa. Monte da Caparica

2829-516 - Caparica - Portugal ima@fct.unl.pt

Maria Inês Nogueira

Professora, Instituto de Ciências Biomédicas/

Universidade de São Paulo.

Av. Professor Lineu Prestes, 2.415

05508-900 - São Paulo - SP - Brasil

minog@usp.br

Francisco Rômulo Monte Ferreira

Professor, Instituto de Psicologia/Universidade de São Paulo.

Av. Professor Mello Morais, 1.721

05508-030 - São Paulo - SP - Brasil

fromulo@usp.br

Recebido para publicação em novembro de 2015.

Aprovado para publicação em agosto de 2016.

http://dx.doi.org/10.1590/S0104-59702016005000029
AMARAL, Isabel; NOGUEIRA, Maria Inês; FERREIRA, Francisco Rômulo Monte. Entre neurônios e sinapses: as contribuições de Cajal e Athias para a medicina ibérica entre os séculos XIX e XX. História, Ciências, Saúde Manguinhos, Rio de Janeiro, v.24, n.1, jan.-mar. 2017, p.187-199.

Resumo

O presente estudo reflete sobre o trajeto da histologia na transição do século XIX para o XX, em Portugal e em Espanha, para estabelecer um paralelo entre as contribuições de Santiago Ramón y Cajal e Marck Athias, ambos determinantes para o desenvolvimento da medicina experimental na Península Ibérica, reconhecidos como pilares de uma nova mentalidade científica europeia, na alvorada do século XX. Neste estudo de caso, refletimos sobre as vicissitudes da construção da ciência na "periferia" europeia, no contexto da categoria historiográfica centro-periferia desenvolvida pelo grupo Science and Technology in the European Periphery (Step), confrontando a realidade ibérica com o modelo de ciência alemã, no período em estudo.

Palavras-chave: teoria neuronal; Santiago Ramón y Cajal (1852-1934); Marck Athias (1875-1946); história da medicina ibérica.

\section{Abstract}

The trajectory of histology at the cusp of the twentieth century in Portugal and Spain is investigated to draw a parallel between the contributions of Santiago Ramón y Cajal and Marck Athias, both of whom were instrumental in the development of experimental medicine in the Iberian Peninsula and recognized as pillars of a new European scientific mindset at the dawn of the twentieth century. In this case study we reflect on the vicissitudes of the construction of science in the "periphery" of Europe, in the context of the historiographical category of center-periphery developed by STEP (Science and Technology in the European Periphery), contrasting the reality in Iberia with the model of German science in the period under study.

Keywords: neuron theory; Santiago Ramón $y$ Cajal (1852-1934); Marck Athias (18751946); history of Iberian medicine. 
E ste trabalho pretende refletir sobre a confluência dos percursos científicos de dois médicos ibéricos contemporâneos, Santiago Ramón y Cajal (1852-1934) e Marck Athias (18751946), para a consolidação de um programa experimental em torno da histologia nervosa. Vários trabalhos têm sido publicados sobre ambos, com destaque para o médico espanhol, pelo que este artigo confere mais detalhe às suas contribuições cruzadas, no domínio da consolidação da teoria neuronal para a ciência espanhola, e, concomitantemente, na modernização da medicina portuguesa influenciada pelo ideal de apostolado científico laico, advogado por Ramón y Cajal. Nesse contexto procuraremos revisitar as contribuições de Athias, menos divulgadas e conhecidas pelos historiadores, e que terão atraído a atenção de Ramón y Cajal. Em simultâneo avaliaremos a influência de Ramón y Cajal em Athias, que, em paralelo com a defesa do modelo alemão de universidade (Vanpaemel, 2012), terá contribuído para a criação de uma escola de investigação em histologia e embriologia, que esteve na origem das principais reformas médicas que ocorreram em Portugal nas primeiras décadas do século XX. Assim procurar-se-á enquadrar essa temática na discussão historiográfica recente dos conceitos "centro" e "periferia" europeus, olhando para a construção e validação global do conhecimento científico (Nieto-Galan, Papanelopoupou, 2006; Gavroglu et al., 2008; Simon, Herran, 2008; Gavroglu, 2012; Patiniotis, Gavroglu, 2012; Patiniotis, 2013; Arabatzis, Renn, Simões, 2015), e não para uma demarcação meramente histórica ou geográfica. Essa aproximação metodológica permitir-nos-á integrar a construção da teoria neuronal, na confluência do protagonismo de Ramón y Cajal e Athias na Península Ibérica, na perspectiva do percurso da histologia nervosa entre os séculos XIX e XX.

\section{A histologia nervosa no século XIX}

A palavra histologia foi proposta em meados de 1819 por Karl Mayer (1787-1865) em substituição ao termo anatomia geral (Maestre de San Juan, 1885). O estudo dos tecidos que compõem os órgãos era uma subdivisão da anatomia denominada anatomia geral.

Uma boa forma de entendermos a divisão que o estudo da anatomia fazia poderá ser através da consulta nos dicionários de termos médicos ao longo do século XIX. No A new medical dictionary, editado por Robert Hooper em 1817, o vocábulo anatomy é definido como a dissecção do corpo humano para a exposição da estrutura, situação e uso de suas partes. Definição muito sintética. Enquanto isso, A dictionary of terms used in medicine and the collateral sciences de 1845, editado por Richard D. Hoblyn, apresentava no verbete anatomy uma divisão bem mais extensa. A anatomia, definida como a ciência da organização, se dividiria em anatomia humana e comparativa, esta última constituindo o estudo da anatomia dos reinos animal e vegetal, excluindo o humano. A anatomia humana, por sua vez, se dividiria em outras quatro áreas: anatomia descritiva, geral, especial e transcendental. À anatomia geral estava confinada a estrutura e propriedade dos diferentes tecidos que são comuns a vários órgãos. A anatomia especial passou a designar-se anatomia patológica na segunda metade do século XIX. A anatomia transcendental, vocacionada para o modo como o molde, plano ou modelo sobre o qual estruturas animais ou órgãos são formados, daria origem à embriologia no final do século. 
Apesar de o termo histologia já ser utilizado em algumas publicações, a denominação anatomia geral ainda prevalecia, conforme o dicionário de termos médicos de 1845 . No dicionário editado por George R. Cutter, em 1879, A dictionary of the german terms used in medicine, existem dois vocábulos que fazem referência à histologia. O substantivo Gewebelehre designa histologia, assim como Histologie, termo mais frequentemente encontrado nas publicações a partir da segunda metade do século XIX. Na busca de outras versões anteriores do dicionário de termos alemães usados em medicina encontram-se os verbetes Gewebe e Gewebeelement, designando, respectivamente, tecido e elemento histológico sem, no entanto, a presença do verbete Gewebelehre.

A designação da histologia por uma ramificação da anatomia permanece nos tratados médicos e nos dicionários até a transição do século XIX para o XX, apesar das inúmeras tentativas de autonomização da histologia (Ramón y Cajal, 1889, 1901, 1917). Um exemplo dessa insistência está patente em An illustrated dictionary of medicine biology and allied sciences, de George Gould (1900).

Mesmo onde a designação por anatomia geral prevalecia, já se apresentava um pensamento histológico característico da autonomia que a histologia alcançaria décadas depois. Exemplo disso é a forma como Louis-Antoine Ranvier (1835-1922) fala do seu mestre, Claude Bernard (1813-1878), a propósito da sua aula inaugural na cátedra de anatomia geral, proferida no Collège de France em 1867:

O problema da fisiologia e da patologia geral é ter como objeto as partes mais interiores e mais essenciais dos órgãos, os elementos dos tecidos. Não é suficiente conhecer anatomicamente os elementos orgânicos, é preciso estudar suas propriedades e suas funções com a ajuda da mais delicada experimentação; em uma palavra, é preciso praticar a histologia experimental. Esse é o objetivo supremo de nossas pesquisas, tal é a base da medicina futura (citado em Berthoz, 2005, p.234).

A disciplina de histologia, assim como os outros ramos da anatomia, nada mais é do que testemunha da funcionalidade do organismo. Essa "subordinação" à fisiologia é razoável se pensarmos na prevalência de uma orientação fisiológica na escola francesa na segunda metade do século XIX, fortemente influenciada pela obra de Claude Bernard. Basta olhar para as principais cátedras nas principais instituições francesas na segunda metade do século XIX para constatar o enorme número de pesquisadores que se formaram sob a égide da medicina experimental professada por Bernard, de forte orientação fisiológica (Flourens, 1971, 2010; Singer, 1947).

A histologia, fundada por Marie François Xavier Bichat (1771-1802), assume a partir da segunda metade do século XIX um papel central nos estudos que agrupamos pela expressão "ciências biomédicas". Esse estatuto alcançado pela histologia pode ser explicado em função do quão bem-sucedida foi a teoria celular como elemento teórico unificador da biologia.

Com novos microscópios e novas técnicas de fixação e coloração histoquímica das lâminas na segunda metade do século XIX, as pesquisas direcionadas para a estrutura do sistema nervoso puderam avançar. Jan Evangelista Purkinje (1787-1869) foi um dos pioneiros no início do século, e, supostamente, a primeira ilustração da estrutura anatômica do tecido nervoso é de sua autoria (Defelipe, 2007). Em 1837, em um congresso científico em Praga, Purkinje apresentou seu trabalho sobre a descrição de células do cerebelo. 
Aproximadamente um ano após a publicação de Purkinje, Matthias Schleiden (18041881) propôs a teoria celular para as plantas. Um ano depois, Theodor Schwann (1810-1882) descobriu a pepsina em tecido animal e propôs a existência das células como unidade básica também no reino animal (Finger, 1994, 2000).

Para Radl (1988), a teoria proposta por Schleiden era "vaga e pouco definida", no entanto, histologistas de renome, tais como Albert Kölliker (1817-1905), Rudolf Virchow (1821-1902), Eduard A. Strasburger (1844-1912), entre outros, aceitaram as concepções de Schleiden e direcionaram suas pesquisas com o objetivo de investigar os elementos que compunham a estrutura celular. Desse programa de pesquisa, os estudos sobre a constituição da célula avançaram até o conhecimento do protoplasma e do núcleo celular, e o aperfeiçoamento de técnicas de coloração das diferentes estruturas celulares, capazes de derivarem uma interpretação consitente entre a estrutura, a função e o mecanismo de funcionamento do tecido nervoso (Mazzarello, 1999). Ramón y Cajal nos fornece um importante testemunho de como foi modificada a teoria celular originalmente proposta no início do século XIX, em meados da década de 1880. Citamos Ramón y Cajal (1880, p.299):

Dos três elementos que constituem a célula, membrana, núcleo e substância albuminoide, nem todos gozam de igual posição hierárquica orgânica. Nem são tampouco necessários para o desempenho de suas variadas funções. Tão somente o protoplasma, essa substância transparente, granulosa e complexa, associada por princípios de hidrocarbonetos e proteínas, é indispensável para a vida da célula; o núcleo e demais fatores do elemento orgânico representam não mais que a diferenciação avançada do mesmo e uma fase especial de sua incessante evolução. Para chegarmos a esse conhecimento foi necessário que Cohn publicasse suas observações sobre os zooporos [gênero de protistas semelhantes a fungos] das algas, elementos mais simples que a célula, pois carecem de membrana; Remak demonstrou igualmente sua ausência [de membrana] nos elementos embrionários que resultam da segmentação do óvulo; Haeckel descobriu todo um reino de seres orgânicos, de formas vagas, indecisas, terreno neutro de onde partem como raios de um mesmo foco o reino vegetal e o animal e no qual se admiram organismos tão simples como o gimnocytodo que não consiste mais que em um pedaço de substância proteica, sem núcleo nem membrana; e, por último, Huxley descobriu o misterioso bathybius haeckelii, essa massa disforme, mucilaginosa que cobre o lodo do fundo dos mares, torpe esboço da organização e que, não obstante, goza das propriedades principais da matéria viva; a nutrição, sensibilidade e reprodução. ${ }^{1}$

Após esses trabalhos descritos acima por Ramón y Cajal, a célula como unidade fundamental dos organismos vivos cede lugar ao protoplasma, essa substância que preenche as células (Beale, 1870), fornecendo assim subsídios para o conhecimento funcional e patológico e para a construção da teoria neuronal.

A teoria neuronal foi formulada por Santiago Ramón y Cajal em 1891 para explicar a constituição histológica do sistema nervoso, em especial as conexões entre os elementos que o compõem (Shepherd, 1991; Ferreira, 2013); em 1888, ele demonstrara a individualidade da célula nervosa, sendo considerado o fundador da teoria neuronal. Várias foram as contribuições dadas por histologistas e fisiologistas da época para a compreensão do funcionamento do sistema nervoso com base nessa teoria, que também Marck Athias defendia em Portugal e para a qual fez algumas contribuições. 


\section{Ramón y Cajal, Athias e o lugar da medicina experimental na Peninsula Ibérica}

Quando Marck Athias chegou a Portugal, a investigação experimental na medicina era muito reduzida (Mira, 1947; Macedo, 2000), pois o ensino médico era essencialmente livresco e teórico. Ainda assim, existiam condições para despertar um cadinho de interesses em torno da valorização da componente experimental na prática clínica, associadas a algumas instituições. Coimbra e Porto tinham dado início ao ensino prático da histologia em finais do século XIX, e Lisboa tinha dois potenciais centros para o desenvolvimento tanto da fisiologia como da histologia: o Instituto Bacteriológico de Lisboa (anexo ao Hospital de São José) e o Hospital de Rilhafoles, ambos equipados com um laboratório de histologia, criados em 1882 e 1897, respectivamente (Sousa-Dias, 2011).

Se compararmos as datas de 1882 e de 1897 com aquelas que marcaram a criação das grandes instituições de ciências biomédicas na transição do século XIX para o XX verificamos que, de alguma forma, existe paralelismo com a fundação dos principais centros de investigação biomédica na Europa e nos Estados Unidos. O Instituto Pasteur de Paris tinha sido criado em 1886; o Laboratório de Biologia Ramón y Cajal, em 1901, em Madri; o Rockefeller Institute, em Nova York, em 1904; e os Institutos Kaiser Wilhelm, na Alemanha, a partir de 1911 (Alves, 1999). Porém, existe uma diferença fundamental: ao contrário de Portugal, nesses países a formação desses institutos assentou numa tradição já bem consolidada de investigação experimental que se tinha iniciado no meio universitário, nos primeiros anos do segundo quartel do século XIX. Os médicos mais interessados na investigação e no ensino prático da fisiologia e da histologia foram Miguel Bombarda (1851-1910) e Luís da Câmara Pestana (1863-1899). Bombarda considerava a fisiologia fundamental no ensino médico e, porque não fazia investigação, procurou rodear-se de alguns colaboradores que por ela se interessassem. Câmara Pestana, cirurgião dos hospitais civis de Lisboa, foi um dos seus primeiros preparadores e colaboradores no ensino prático da histologia, então parte da disciplina de fisiologia. Os bacteriologistas que se associaram a Câmara Pestana foram pioneiros na criação de um ambiente de investigação semelhante ao dos institutos alemães e de uma produção científica considerada de grande valor científico. Pelo reconhecimento do seu trabalho e por necessidade de combate eficaz contra a raiva e a difteria, o Estado português criou o Real Instituto Bacteriológico em 1895, que, após a morte precoce de Câmara Pestana, em 1899, recebeu o seu nome (Borges et al., 2008).

Câmara Pestana desviou os seus interesses para o domínio da bacteriologia, e Miguel Bombarda convidou Marck Athias para assumir a liderança do laboratório de histologia, do qual era diretor (Costa, 1948). Bombarda interessou-se por Athias de uma forma particular, uma vez que partilhava das suas ideias sobre a teoria do neurônio, proposta por Ramón y Cajal, que lhe interessava para as suas reflexões no âmbito da psiquiatria, a sua cátedra (Amaral, 2006d).

O laboratório de Athias passou a ser frequentado por vários colaboradores, alguns deles provenientes do laboratório de Câmara Pestana. A histologia experimental, em Lisboa, passou a ser desenvolvida a partir destes dois laboratórios: o de histologia do Hospital de Rilhafoles e o do Instituto Bacteriológico Câmara Pestana. No laboratório de histologia do Hospital de Rilhafoles deu-se início a uma nova fase da medicina experimental portuguesa, da qual 
Marck Athias se tornaria o protagonista, formando uma escola de investigação, na acepção de Gerald Geison (Geison, Holmes, 1993).

O programa da escola de Marck Athias teve cinco linhas de investigação que se sucederam ao longo do tempo: a histologia do sistema nervoso, a histofisiologia, a histopatologia, a fisiologia e a química fisiológica. É um programa que transita entre o estado normal e o estado patológico, fazendo uso das teorias de relação causa/efeito e das técnicas de visualização em voga na Europa, particularmente as que utilizou na histologia do sistema nervoso, iguais ou similares às que Ramón y Cajal utilizava em Madri (Rámon y Cajal, 1889, 1901).

A linha de investigação em histologia nervosa iniciada em Paris, no laboratório de Mathias Duval (1844-1907), professor de Athias, foi a que menos tempo durou e a que produziu menor número de publicações científicas (somente 7\%), porque foi interrompida com a sua vinda para Lisboa. Tinha-se diluído o contato direto com Mathias Duval, e os interesses da comunidade médica portuguesa condicionaram a dispersar-se por outras áreas de investigação. Para além dos trabalhos realizados por si e por Carlos França (1877-1926) entre 1906 e 1915 (Amaral, 2002), as contribuições que mais aproximam Athias de Cajal foram realizadas apenas entre 1895 e 1898. Por ter sido o período mais breve na sua carreira de investigador terão sido menos estudadas até ao momento.

No laboratório de Duval, Athias utilizou o método de Golgi (11 dez. 1906) para estudar a histogénese do cerebelo. Essa técnica, publicada em 1883 nos Archivi Italiani di Neurologia, apenas teve impacto fora de Itália. Foi depois publicada na monografia de 1886, Sulla fina anatomía degli organi centrali del sistema nervoso, mas teve também uma escassa divulgação. Nesse conjunto reduzido de conhecedores da técnica estavam Ramón y Cajal e Athias. Envolvendo as peças histológicas em fragmentos de pão ázimo para impedir a formação de cristais, Athias contribuiu para a fundamentação da teoria neuronal, ao confirmar alguns dos resultados apontados por Ramón y Cajal (Athias, 1941), nomeadamente os apresentados no Congresso de Anatomia realizado em Berlim em 1889 (Sotelo, 2003), que permitiam demonstrar a individualidade histológica e funcional da célula nervosa.

Athias escolheu as células epiteliais da medula de rã, analisou o processo de desenvolvimento embrionário do neurônio a partir dos neuroblastos (células primitivas) e concluiu que células do mesmo gênero, observadas por Ramón y Cajal cinco anos antes na medula espinhal de frango (Ramón y Cajal, 1890), passavam por três fases sucessivas (Athias, 1895a): uma fase epitelial ou bipolar, durante a qual a célula conservava ainda uma posição convergente entre os esfingoblastos e uma expansão epidendimal ou interna; uma fase unipolar (neuroblasto de His), que surgia em consequência de uma atrofia mais ou menos completa da expansão epidendimal; e a terceira fase, multipolar, que surgia como consequência das projeções protoplasmáticas do corpo celular da porção mais imediata das expansões primordiais (Athias, 1895b). Estudando depois a origem e evolução das pequenas células estreladas da camada molecular do cerebelo de gatos e coelhos, com idades compreendidas entre um e 15 dias, concluiu que essas células provêm de elementos epitelioides, que, no decorrer do desenvolvimento, se transformam em células estreladas que se dispõem horizontalmente e que se colocam perpendicularmente ao eixo longitudinal das lamelas (Athias, 1896). Esses resultados permitiram esclarecer e reforçar a concepção da polaridade dos prolongamentos 
protoplasmáticos (dendritos) e do axônio, explicando assim a transmissão dos impulsos elétricos: a célula epitelioide, antes de se deslocar, aderia à periferia do cerebelo através de um prolongamento espesso, protoplasmático, enquanto a sua parte profunda emitia o filamento axonal (Athias, 1897a, 1897b). Esses resultados corroboravam a teoria neuronal ao explicar a conexão entre os diferentes elementos de comunicação nas células nervosas, observados no processo de desenvolvimento celular (Athias, 1898).

Essas contribuições de Marck Athias são consideradas como referência na concepção da estrutura do sistema nervoso na década de 1920, que se situa também na equação da teoria neuronal, entre neurônios e sinapses. Ramón y Cajal considerava o médico português um dos pioneiros da sua própria teoria (Ramón y Cajal, 1952, p.37; Athias, 1934). Athias tinha demonstrado a origem epitelial comum de elementos nervosos e neuróglicos (terminologia utilizada para designar as células gliais hoje, células que servem para manter a homeostase, formar a mielina e atuar como proteção e suporte aos neurônios); estabeleceu a origem e filiação das várias espécies celulares do cerebelo e provou a equivalência, como elemento receptor, da sinapse do soma e dos dendritos.

\section{A confluência de atitudes nas obras de Ramón y Cajal e Athias}

Quando Ramón y Cajal iníciou seus estudos do sistema nervoso, as técnicas histológicas eram pouco fiáveis e os conhecimentos bioquímicos estavam numa fase embrionária. Por outro lado, o sistema nervoso era ainda pouco conhecido. Se a esses condicionalismos associarmos a ausência de uma forte tradição científica capaz de envolver e dinamizar a comunidade científica difundindo as suas contribuições intra e extramuros, facilmente nos aperceberemos da singularidade de Ramón y Cajal no contexto ibérico.

A teoria neuronal teria dificuldade em ser aceita pelos seus pares por ser suficientemente controversa. Na época, considerava-se que o sistema nervoso central se constituía no nível tecidual por um conjunto de filamentos unidos de forma contínua e difusa - teoria reticular -, e Ramón y Cajal defendia o contrário. Ele admitia a independência anatômica das células nervosas e o contato entre elas por contiguidade, recusando a ideia de anastomose entre as células. Dessa forma, Ramón y Cajal introduziu uma ruptura paradigmática na história da "neurologia", que inicialmente foi olhada com alguma desconfiança pela ciência europeia (López-Muñoz, Boya, Alamo, 2006; De Carlos, Borrell, 2007; De Castro, López-Mascaraque, De Carlos, 2007).

No ano de 1888, num momento significativo de viragem na sua carreira científica, Rámon y Cajal estava determinado a lutar pela sua teoria (Ramón y Cajal, 1894). Publicou 18 trabalhos em apenas seis meses, na Gaceta Médica Catalana e na Revista Trimestral de Histología Normal y Patológica, um periódico destinado a publicar os trabalhos do Laboratório de Histologia da Universidade de Barcelona. Publicou também o primeiro artigo Observations sur le texture des fibres musculaires des pattes et des ailes des insects, na revista alemã Internationale Monatsschrift fur Anatomie und Physiologie. Ainda assim, os resultados de Ramón y Cajal continuavam a ser desconhecidos. Ciente de que trabalhar de forma isolada e publicar numa língua que a Europa (os principais centros científicos) não dominava, resolveu traduzir os seus artigos para francês e enviá-los para revistas alemãs. Propôs estabelecer contato com os histologistas europeus mais 
eminentes do seu tempo. Com os seus próprios rendimentos deslocou-se a Berlim em 1889, e acompanhado pelo seu microscópio e pelas suas preparações, fez um périplo pela Alemanha e Itália visitando diversos laboratórios de investigação, onde contatou vários cientistas que perceberam a amplitude do seu trabalho (em Pavia, Ramón y Cajal esperava encontrar Camillo Golgi, mas o mesmo estava viajando em um de seus inumeros compromissos como senador). Após regressar a Espanha continuou a estruturar a sua teoria. Em 1890, publicou o primeiro manual de histologia espanhol com a teoria neuronal, Manual de anatomía patológica general, que viria a transformar-se num dos textos clássicos que se manteve atualizado até à primeira metade do século XX. A partir de então algumas obras começaram a ser traduzidas, e Ramón y Cajal passou a ser convidado pelas principais sociedades científicas internacionais. Em 1894, proferiu a Croonian Lecture a convite da Royal Society de Londres; ao terminar a sua exposição, recebeu o doutoramento Honoris causa pela Universidade de Cambridge, ao qual se seguiram várias homenagens por diversas universidades de Itália, Alemanha, Áustria, França e Peru. Em 11 de dezembro de 1895 foi nomeado, sob proposta de Rudolf Virchow, membro da Real Academia de Ciencias Exactas, Físicas y Naturales da Espanha. No seu discurso inaugural apontou algumas regras para a investigação científica, que depois publicou em livro, Reglas y consejos sobre investigación científica. Dizia ele aos jovens investigadores que estas seriam as regras para triunfarem na periferia:

Para produzir um Galileu ou um Newton é preciso uma legião de investigadores estimáveis ... Enquanto nossas raças têm dormido secularmente do sonho da ignorância e cultivado a religião e a arte - preferencialmente e quase únicas atividades de povos primitivos - as nações do centro da Europa têm se adiantado progressivamente (Salas, 2003, p.35).

A partir de 1901, o governo espanhol criou para Ramón y Cajal o Laboratório de Investigações Biológicas a partir do qual se estabeleceu a escola espanhola de neuro-histologia, um dos centros de investigação mais prestigiados do país. A consagração de Ramón y Cajal só veio em 1906, com a atribuição do Prêmio Nobel (Rámon y Cajal, 12 dez. 1906). Dessa forma, Santiago Ramón y Cajal passou a ser reconhecido como um histologista singular.

A carreia de Athias foi marcadamente influenciada pela obra de Ramón y Cajal. Ainda estudante, na Faculdade de Medicina de Paris, interessou-se pela histologia do sistema nervoso ao encontrar, na estante de uma livraria, a obra Les nouvelles idées sur la structure du système nerveux. De imediato propôs a Mathias Duval, um antigo discípulo de Ramón y Cajal, que lecionava na faculdade, que o aceitasse no seu laboratório. Dessa colaboração resultaram cinco publicações e a sua tese inaugural, intitulada Histogènese du cortex cérébelleux, que lhe valeu a atribuição da medalha comemorativa da Faculdade de Medicina de Paris e uma condecoração do Ministério da Educação francês. Ao terminar o curso, teria preferido continuar no laboratório de Duval, mas foi preterido, em concurso, a favor de outro discípulo de Duval, de nacionalidade francesa. Esse incidente conduziu-o a Lisboa e a Miguel Bombarda, que como ele defendia a teoria neuronal. Tudo indicava que desse contiuidade à investigação no domínio da histologia nervosa, mas tal não aconteceu, porque os interesses da investigação médica em Lisboa estavam centrados fundamentalmente na bacteriologia (Amaral, 2006a).

A investigação de Athias em Paris contribuiu para reforçar a teoria neuronal, que rivalizava com a teoria reticularista, mas a influência de Ramón y Cajal em Athias ultrapassaria as 
fronteiras científicas. Quando Marck Athias se preparava para abandonar a Faculdade de Medicina, entregou o seu espólio, constituído por livros, separatas e correspondência, à biblioteca de histologia, e a Celestino da Costa, um dos seus discípulos, deixou algumas daquelas separatas científicas e 15 caixas com preparações histológicas. No conjunto dessas separatas encontrava-se também o livro de Ramón y Cajal com o seguinte comentário: "este foi o livro que fez a minha desgraça”. A "desgraça” a que alude será certamente o apostolado laico que Ramón y Cajal preconizava e que, para a escola de Athias, foi suporte para a investigação científica (Costa, 1954). Dizia Ramón y Cajal: “entre os sentimentos que devem animar ao homem de ciência merece menção o patriotismo. Esse sentimento tem no sábio signo exclusivamente positivo, anseio em elevar o prestígio de sua pátria, mas sem denegrir as demais" (Ramón y Cajal, 1898, p.64). E ainda, noutra passagem, "as qualidades indispensáveis ao cultivador da pesquisa são: a independência neutra, a curiosidade intelectual, a perseverança no trabalho, a religião da pátria e o amor à glória" (p.149). Notas de um positivista laico que se escoram na modenização da medicina portuguesa pela geração de 1911 (Amaral, 2011) muito influenciada por Marck Athias. Os seus discípulos reconheceram, nas homenagens que lhe prestaram, o gosto e a dedicação à prática laboratorial como complemento à prática clínica; o rigor e perfeição nas preparações histológicas, na interpretação dos resultados experimentais e nas conclusões; o apetrechamento das bibliotecas dos institutos da Faculdade de Medicina (Costa, 1935); a criação e dinamização das principais sociedades científicas biológicas existentes no país, e, particularmente, a entrega incondicional à promoção da investigação científica e ao seu "culto", como mote de modernização das ciências médicas (Amaral, 2006a), e, em última análise, do país.

A sua singularidade em Portugal e a escassez de figuras com formação semelhante na época tornaram-no o centro das grandes inovações sentidas nas reformas do ensino médico em Portugal (Amaral, 2006c). A formação marcadamente experimental realizada na Faculdade de Medicina de Paris e a influência de Ramón y Cajal (nos planos científico e doutrinal) foram determinantes para tomar consciência da importância de formar discípulos e de fazer escola (Amaral, 2003), pelo que, logo que iniciou a sua atividade científica em Portugal foi congregando em torno de si jovens interessados em prosseguir uma carreira científica. Recrutados majoritariamente na Escola Médica de Lisboa e unidos por um ideal comum de universidade e de investigação científica (Vanpaemel, 2012), constituíram um grupo coeso e com identidade própria que perdurarou até a segunda geração de discípulos. A sua intervenção nos institutos de investigação que dirigia, nos periódicos científicos e de divulgação que fundou ou secretariou, ou ainda em orgãos reguladores da política científica nacional é incontornável no desenvolvimento da ciência e da medicina portuguesas (Amaral, 2006b).

Apesar da projeção distinta que ambos tiveram na sua época à escala internacional, a semelhança entre a obra de Ramón y Cajal e a de Athias e dos contextos em que se desenvolveram é particularmente evidente num conjunto de aspectos que aproximam os seus respectivos países, ambos "periféricos", numa dialética de continuidades e descontinuidades que demonstram a importância que essas duas figuras tiveram para a modernização da medicina portuguesa e espanhola e, por consequência, global. A falta de reconhecimento da validade da teoria neuronal, pelo fato de ela provir de um cientista de um país sem tradição científica como a Espanha, encontra paralelo no quase desconhecimento dos trabalhos de 
Athias que, apesar de referidos no tratado de anatomia de Testut (Testut, Latarget, 1900) e do esforço de publicar em francês, quase passaram despercebidos na comunidade científica não só internacional, como nacional também. Ainda hoje alguns historiadores da medicina pouco conhecem a obra de Athias por este ter sido um médico que vivia no e para o laboratório, e não para a clínica.

A centralidade da ciência francesa e alemã foi aceitando paulatinamente a importância da teoria neuronal proposta por Ramón y Cajal, treinado na "periferia" científica, que inverteu os polos de influência e passou a ocupar o "centro" (Gavroglu et al., 2008; Patiniotis, 2013). Em paralelo, a filiação de Athias na ideologia e na prática científica de Ramón y Cajal tornou-se a alavanca fundamental para o progresso da ciência e da medicina experimental portuguesa, numa lógica de adesão e apropriação do modelo do médico espanhol (Patiniotis, Gavroglu, 2012). Estes dois exemplos, Ramón y Cajal e Athias, não deixam em aberto um conjunto de questões sobre a visibilidade que contribuições como essas poderão ter para uma discussão mais abrangente sobre a emergência de novas áreas disciplinares, como a histologia, na transição do século XIX para o século XX, no contexto europeu, ou na construção da narrativa de um conhecimento global a partir de realidades e de tradições científicas locais, que vivem de continuidades e descontinuidades (Simon, Herran, 2008) e que alteram o sentido dos polos da hegemonia científica (Patiniotis, 2013), problemáticas recentemente discutidas pelo Step (Arabatzis, Renn, Simões, 2015).

\section{NOTA}

${ }^{1}$ Nessa e nas demais citações de textos em espanhol, a tradução é livre.

\section{REFERÊNCIAS}

ALVES, Manuel Valente.

1911 - O ensino médico em Lisboa no início do século: sete artistas contemporâneos evocam a geração médica de 1911. Lisboa: Fundação Calouste Gulbenkian. 1999.

AMARAL, Isabel.

A nova face da medicina portuguesa: a geração de 1911 e a escola de investigação de Marck Athias. Acta Medica Portuguesa, v.24, p.155-162. 2011.

AMARAL, Isabel.

A emergência da bioquímica em Portugal: as escolas de investigação de Marck Athias e de Kurt Jacobsohn. Coleção Textos Universitários de Ciências Sociais e Humanas. Lisboa: FCG/FCT. $2006 a$.

AMARAL, Isabel.

The emergence of new scientific discipines in Portuguese medicine: Marck Athias's histophysiology research school, Lisbon (18971946). Annals of Science, v.63, n.1 p.85-110. 2006b.
AMARAL, Isabel.

Na vanguarda da modernidade: o dinamismo sinergético de Marck Athias, Celestino da Costa e Ferreira de Mira na primeira metade do século XX. In: Pereira, Ana Leonor; Pita, João Rui. Estudos do século XX. Coimbra: Ariadne. p.263282. 2006c.

AMARAL, Isabel.

Miguel Bombarda e a Escola de Investigação de Marck Athias (1897-1910). In: Pereira, Ana Leonor; Pita, João Rui. Miguel Bombarda e as singularidades de uma época. Coimbra: Imprensa da Universidade de Coimbra. p.155-162. 2006d.

AMARAL, Isabel.

A escola de investigação de Marck Athias e o surgimento de novas disciplinas médicas entre 1897 e 1946. In: A ciência em Portugal na primeira metade do século $X X$. Évora: S. Reprografia e Publicações da Universidade de Évora. p.251-262. 2003.

AMARAL, Isabel.

As escolas de investigação de Marck Athias e de Kurt Jacobsohn e a emergência da bioquímica 
em Portugal. Dissertação (Doutorado em Epistemologia das Ciências) - Universidade Nova de Lisboa, Lisboa. 2002.

ARABATZIS, Theodore; RENN, Jürgen; SIMÕES, Ana (Ed.).

Relocating the history of science: essays in honor of Kostas Gavroglu. Boston Studies in the Philosophy and History of Science. Dordrecht: Springer. 2015.

ATHIAS, Marck.

O cinquentenário da teoria do neurónio. Lisboa: Imprensa Lucas. 1941.

ATHIAS, Marck.

Santiago Ramón y Cajal. Lisboa Médica, v.11, p.831-853. 1934.

ATHIAS, Marck.

Histogénese do sistema nervoso. A Medicina Contemporânea (II Série), ano 16, v.70, n.83, p.113. 1898.

ATHIAS, Marck.

Structure histologique de la moelle épinière du têtard de le grenouille. Bibliographie Anatomique, v.5, p.58-60. 1897a.

ATHIAS, Marck.

Recherches sur l'histogénèse de l'écorce du cervelet. Journal d'Anatomie, v.33, p.372-373. 1897b.

ATHIAS, Marck.

Sur l'origine et l'evolution des petites cellules étoilées de la couche moléculaire du cervelet chez le chat et le lapin. Comptes Rendus de la Société de Biologie de Paris, séance du 12 juin, p.585-586. 1896.

ATHIAS, Marck.

Cellulles nerveuses encore epithéliales dans la moelle du tetard de la grenouille. Mode de développement du neurone. Comptes Rendus de la Société de Biologie de Paris, séance du 6 juillet, p.540-541. 1895a.

ATHIAS, Marck.

Cellulles nerveuses en developpement dans la moelle épinière du tétard de la grenouille. Journal d'Anatomie, n.31, p.610. 1895b.

BEALE, Lionel S.

Protoplasm; or, life, force, and matter. London: J. Churchill \& Sons. 1870.

BERTHOZ, A. (Org.).

Lições sobre o corpo, o cérebro e a mente: as raízes das ciências do conhecimento no Collège de France. Bauru: Edusc. 2005.

BORGES, Juvenália et al.

Luis da Câmara Pestana: uma vida curta, uma obra enorme. Funchal: Empresa Municipal "Funchal 500 anos". 2008.
COSTA, Augusto Celestino da.

Ramón y Cajal (1852-1934). O médico, separata, v.126, p.1-26. 1954.

COSTA, Augusto Celestino da.

A vida e obra científica de Marck Athias. Arquivo de Anatomia e Antropologia, v.26, p.145-227. 1948.

COSTA, Augusto P. Celestino da.

O professor Marck Athias. Folia Anatomica, v.10, p.3-10. 1935.

DE CARLOS, Juan A., BORRELL, José.

A historical reflection of the contributions of Cajal and Golgi to the foundations of neuroscience. Brain Research Reviews, v.55, p.8-16. 2007.

DE CASTRO, F.; LÓPEZ-MASCARAQUE, L.; DE CARLOS, J.A.

Cajal: lessons on brain development. Brain

Research Reviews, v.55, n.2, p.481-489. 2007.

DEFELIPE, Javier.

Cajal y la neurociencia del siglo XXI. In: DeFelipe, J. et al. Paisajes neuronales: homenaje a Santiago Ramón y Cajal. Madrid: Consejo Superior de Investigaciones Científicas. p.41-97. 2007.

FERREIRA, Francisco R.M.

A teoria neuronal de Santiago Ramón y Cajal. Tese (Doutorado) - Universidade de São Paulo, São Paulo. 2013.

FINGER, Stanley.

Minds behind the brain: a history of the pioneers and their discoveries. New York: Oxford University Press. 2000.

FINGER, Stanley.

Origins of neuroscience: a history of explorations into brain function. New York: Oxford University Press. 1994.

FLOURENS, Pierre M.J.

Eloge historique de François Magendie. United States: Kessinger Publishing. [1858] 2010.

FLOURENS, Pierre M.J.

A unidade do sistema nervoso. [1824]. In: Boring, E.G.; Herrnstein, R.J. (Org.). Textos básicos de história da psicologia. São Paulo: Editora Herder. p.270-279. 1971.

GAVROGLU, Kostas.

The STEP (Science and technology in the European Periphery) initiative: attempting to historicize the notion of European science. Centaurus, v.54, p.311-327. 2012.

GAVROGLU, Kostas et al.

Science and technology in the European periphery: some historiographical reflections. History of Science, v.46, p.153-175. 2008. 
GEISON, Gerald; HOLMES, Frederic.

Research schools: historical reappraisals. Osiris, v.8. 1993.

GOLGI, Camillo.

The neuron doctrine: theory and facts. Nobel Lecture, 11 dez. 1906.

GOULD, George M.

An illustrated dictionary of medicine, biology and allied sciences. Philadelphia: P. Blakiston, Son \& Co. 1900.

LÓPEZ-MUÑOZ, Francisco; BOYA, Jesus; ALAMO, Cecilio.

Neuron theory, the cornerstone of neuroscience, on the centenary of the Nobel Prize award to Santiago Ramón y Cajal. Brain Resaerch Bulletin, v.70, n.4-6, p.391-405. 2006.

MACEDO, Manuel M.

História da medicina portuguesa no século XX. Lisboa: CTT Correios de Portugal. 2000.

MAESTRE DE SAN JUAN, Aureliano.

Tratado elemental de histología normal y patológica. Madrid: Nicolas Moya editor. 1885.

MAZZARELLO, Paollo.

A unifying concept: the history of cell theory. Nature Cell Biology, v.1. Disponível em: http:// www.tmd.ac.jp/artsci/biol/textintro/celltheory. pdf. Acesso em: 20 fev. 2015. 1999.

MIRA, Matias B. Ferreira de

História da medicina portuguesa. Lisboa: Edição da Empresa Nacional de Publicidade. 1947.

NIETO-GALAN, Agustí; PAPANELOPOULOU, Faidra.

Science, technology, and the public in the European periphery: A report of the 5STEP meeting. JCOM, v.5, n.4, p.1-6. 2006.

PATINIOTIS, Manolis.

Between the local and the global: history of science in the European periphery meets postcolonial studies. Centaurus, v.55, n.4, p.361-384. 2013.

PATINIOTIS, Manolis; GAVROGLU, Kostas. The sciences in Europe: transmitting centers and the appropriating peripheries. In: Renn, Jürgen (Ed.). Globlization of knowledge in history. Berlin: epubli GmbH. p.321-343. 2012.

RADL, E.M.

Historia de las teorias biológicas: desde Lamarck y Cuvier. Madrid: Alianza editorial. Tomo II. 1988.

RAMÓN Y CAJAL, Santiago.

Cuadernos biograficos II. Madrid: Ediciones de la Direccion Generale de Relaciones Culturales. 1952.
RAMÓN Y CAJAL, Santiago.

Recuerdos de mi vida. Madrid: Libraria de Nicolas Moya. 1917.

RAMÓN Y CAJAL, Santiago.

The structure and connexions of neurons. Nobel Lecture. 12 dez. 1906.

RAMÓN Y CAJAL, Santiago.

Elementos de histología normal y de técnica micrográfica. Madrid: Nicolas Moya. 1901.

RAMÓN Y CAJAL, Santiago.

Reglas y consejos sobre investigación cientifica: los tonicos de la voluntad. Madrid: Espasa Calpe. 1898.

RAMÓN Y CAJAL, Santiago.

The Croonian lecture: la fine structure des centres nerveux. Proceedings of The Royal Society of London, v.55, p.331-335, 444-468. doi:10.1098/ rspl.1894.0063. 1894.

RAMÓN Y CAJAL, Santiago.

A quelle époque apparaissent les expansions des cellulles nerveuses de la moelle épinière du poulet?. Anatomischer Anzeiger, v.5, n.21, 22, p.609-613, 631-639. 1890.

RAMÓN Y CAJAL, Santiago.

Manual de histología normal y técnica micrográfica. Valencia: Imprenta y Librería de Nicolás Moya. 1889.

RAMÓN Y CAJAL, Santiago. El protoplasma: breve análisis de los últimos trabajos publicados acerca de su constitución anatómica. La Clinica, v.153, p.299; v.154, p.306-308; v.155, p.313-315. 1880.

SHEPHERD, Gordon M.

Foundations of the neuron doctrine. New York: Oxford University Press. 1991.

SALAS, Hans M.

Perfiles de Marcel Roche. Revista del Instituto

Nacional de Higiene Rafael Rangel. v.34, n.2, p.12-22. 2003.

SIMON, Josep; HERRAN, Néstor (Ed.).

Beyond borders: fresh perspectives in history of science. Newcastle: Cambridge Scholars Publishing. 2008.

SINGER, Charles J.

Historia de la biologia. Buenos Aires: Espasa-Calpe Argentina. 1947.

SOTELO, Diamantino.

Viewing the brain through the master hand of Ramón y Cajal. Nature Reviews Neuroscience, v.4, p.71-77. 2003. 
SOUSA-DIAS, José Pedro.

O Instituto Bacteriológico: espaço, instrumentos e memória da medicina laboratorial. In:

Lourenço, Marta C.; Neto, Maria João (Ed.).

Património da Universidade de Lisboa. Ciência e Arte. Lisboa: Universidade de Lisboa, Tinta-daChina, p.137-154. 2011.

TESTUT, L.; LATARGET, A.

Compendio de anatomia descritiva. Barcelona:

Salvat Editores. 1900.
VANPAEMEL, Geert.

Laboratory cultures in Europe. The "German model" in The European periphery. In: RocaRosell, Antoni (Ed.). The circulation of science and technology: Proceedings of the 4th International Conference of the ESHS. Barcelona: SCHCT-IEC. p.175-180. 2012. 